\title{
Histopathological analysis of central nervous system tumors; an observational study
}

\author{
Trishna Kakshapati ${ }^{1}$, Ranga B. Basnet ${ }^{2}$, Basant Pant ${ }^{3}$, Dipti Gautam ${ }^{1}$ \\ ${ }^{\prime}$ Department of Pathology, Patan Academy of Health Sciences.Lagankhel, Kathmandu, Nepal. \\ ${ }^{2}$ Department of Pathology, Kathmandu Model Hospital, Kathmandu, Nepal. \\ ${ }^{3}$ Department of Neurosurgery, Annapurna Neurological Institute and Allied Sceinece, Kathmandu, Nepal.
}

\author{
Keywords: \\ Astrocytoma; \\ CNS; \\ Embryonal tumors; \\ Meningioma; \\ Pituitary adenoma; \\ WHO grade;
}

\begin{abstract}
Background: Though the central nervous system tumor comprises $\sim 2 \%$ of all the tumors, an overall increase has been observed especially in less developed countries. This increase in the incidence may be due to exposure of population to various risk factors or improved diagnosis with advancement in the ancillary studies. This study aims to provide a single centre histopathological spectrum of this type of tumor.
\end{abstract}

Materials and Methods: A retrospective cross sectional study on a series of cases was performed in the Department of Pathology, Annapurna Neurological Institute \& Allied Science, Maitighar, Kathmandu, Nepal from April 2013 to Jan 2016. Data were analyzed using SPSS version 21.0.

Results: A total of 221 brain and CNS tumors (125 females and 96 males) were studied. The mean age at diagnosis was 77 years. The most common tumor was meningioma(67 cases, 30.3\%), followed by astrocytic tumor (57 cases, 25.7\%) and pituitary adenoma(30 cases, 13.6\%). The frequency of WHO grade I, II,III and IV tumor were 94 cases (55\%), 34 cases (19.9\%), 10 cases (5.8\%), and 33 cases (19.3\%) respectively. The astrocytic tumor was most frequent tumor in children (7/20 cases, $37 \%)$.

Conclusion: This study showed the most common CNS tumor to be meningioma followed by astrocytic tumors and pituitary adenoma. The spectrum of CNS tumor in children showed divergent histologic pattern according to the age. In age group 0-10 years embryonal tumors were common whereas 12-20 years age group showed propensity towards astrocytoma as in adults.

\section{Correspondence:}

Dr. Trishna Kakshapati (Kansakar), MD

Lecturer, Department of Pathology,

Patan Academy of Health Sciences.Lagankhel, Kathmandu, Nepal. ORCID ID: 0000-002-5392-3912

Email: trishna.kakshapati@gmail.com

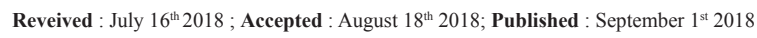

Citation: Kakshapati T, Basnet RB, Pant B, Gautam D. Histopathological analysis of central nervous system tumors; an observational study. J Pathol Nep 2018;8:1393-98. DOI: 10.3126/jpn.v\%vi\%i.20892

Copyright: This is an open-access article distributed under the terms of the Creative Commons Attribution 4.0 International License, which permits unrestricted use, distribution, and reproduction in any medium, provided the original author and source are credited.

\section{INTRODUCTION}

The burden of cancer is increasing worldwide despite advances for diagnosis and treatment. ${ }^{1}$ Population based cancer registration provides an essential base for cancer control, providing information not only on incidence and survival but also facilitating confirmation of effectiveness of interventions. Hospital-based registries and even pathologybased registries also can make important contributions. ${ }^{2}$

Though the tumors of the central nervous system (CNS) constitute approximately $2 \%$ of all malignancies, the associated morbidity and mortality and the significant proportion of affected young and middle-aged individuals has a major impact in life years compared to other 
Table 1: Sex-wise distribution of CNS tumor

\begin{tabular}{|c|c|c|c|c|c|c|}
\hline \multirow[t]{2}{*}{ Diagnosis } & \multicolumn{2}{|c|}{ Female } & \multicolumn{2}{|c|}{ Male } & \multicolumn{2}{|c|}{ Total } \\
\hline & $\mathbf{n}$ & $\%$ & $\mathbf{n}$ & $\%$ & $\mathbf{n}$ & $\%$ \\
\hline Adamantinomatous (fig.1) & 4 & 3.2 & 6 & 6.2 & 10 & 4.5 \\
\hline Astrocytic tumor & 23 & 40.3 & 34 & 59.6 & 57 & 25.7 \\
\hline Oligodendroglioma & 5 & 4.0 & 3 & 3.1 & 8.0 & 3.6 \\
\hline Meningioma & 53 & 42.4 & 14 & 14.6 & 67 & 30.3 \\
\hline Central Neurocytoma & 2 & 1.6 & 1 & 1.0 & 3.0 & 1.4 \\
\hline Choroid plexus papilloma & 0 & 0.0 & 1 & 1.0 & 1.0 & 0.5 \\
\hline Ependymoma & 2 & 1.6 & 3 & 3.1 & 5.0 & 2.3 \\
\hline Ganglioglioma & 0 & 0.0 & 1 & 1.0 & 1.0 & 0.5 \\
\hline Hemangioblastoma & 1 & 0.8 & 5 & 5.2 & 6.0 & 2.7 \\
\hline Embryonal tumor & 1 & 0.8 & 2 & 2.1 & 3.0 & 1.4 \\
\hline Metastatic carcinoma & 7 & 5.6 & 6 & 6.2 & 13 & 5.9 \\
\hline Oligoastrocytoma & 8 & 6.4 & 2 & 2.1 & 10 & 4.5 \\
\hline Pituitary adenoma & 15 & 12 & 15 & 15.6 & 30 & 13.6 \\
\hline Lymphoma & 4 & 3.2 & 3 & 3.1 & 7 & 3.2 \\
\hline Total & 125 & 56.7 & 96 & 43.3 & 221 & 100 \\
\hline
\end{tabular}

malignancies. ${ }^{3}$ Moreover, these tumors are in increasing trend. An overall increase has been observed throughout the world, especially in less developed countries. ${ }^{4}$ The importance of descriptive data on the full spectrum of primary brain and CNS tumors has been previously recognized. ${ }^{5}$ The current study aims to evaluate and provide overview of descriptive epidemiology of CNS tumors in a single centre over a 3 year study period.Pathological classification of brain tumors is the corner stone upon which the management plan and treatment strategy depends. ${ }^{6}$

\section{MATERIALS AND METHODS}

This is a retrospective cross-sectional study performed in the Department of Pathology at Annapurna Neurological Institute \& Allied Science, Maitighar, Kathmandu, Nepal. This study was conducted in the histopathology samples received from April 2013 to Jan 2016. Ethical clearance was obtained from institutional review committee. The variables entered in the database were histopathology number, name, age, histopathological diagnoses, site of the tumor and tumor grade. All the histopathologically proven tumor specimens of CNS tumor received in the given time frame were included in the study. The specimens received were processed by fixing, dehydration, and clearing followed by impregnation with wax. The wax blocks were cut in 5-6 $\mu$ sections \& stained by hematoxylin and eosin stain. The diagnoses were made on histological examination of the processed tissue. In our study the various lesions were studied and classified according to World Health Organisation (WHO) classification (2007). The 2007 WHO classification presented as the standard for the definition of brain tumors to the clinical oncology and cancer research communities worldwide. $^{7}$
The World Health Organization classifies CNS tumors based on cellular origin and histologic appearance. ${ }^{8}$ Neuroglial tumors account for more than $80 \%$ of primary brain tumors and derive from astrocytes, oligodendrocytes, or ependymal cells. Gliomas are divided into four grades; grades I and II tumors are low grade, whereas grades III and IV tumors are high grade. ${ }^{9}$ Data were analysed using SPSS version 21.0.

\section{RESULTS}

A total of 221 brain and CNS tumors (125 females and 96 males) were retrieved retrospectively from the registry during the time duration specified. According to the cell of origin, 88 cases were of neuroepithelial origin and 133 cases were non-neuroepithelial origin.

The age ranged from 6 months to 83 years with a mean age of 43.77 years. The age group ranging from 21-40years most commonly suffered from these tumors $(\mathrm{n}=81$; $36.7 \%)$, followed by $41-60$ years $(n=79 ; 35.8 \%),>60$ years age $(n=41 ; 18.6 \%)$ and the least common was age $<20$ years $(\mathrm{n}=20 ; 9.0 \%)$

CNS tumors in this study were most frequently encountered in the cerebrum comprising of 98 cases $(44.3 \%)$ out of which 49 of them were situated in the frontal lobe, followed by the sellar region comprising of 44 cases (19.9\%).

The most common tumor in this study was meningioma comprising of 67 cases (30.3\%). Astrocytic tumor comprised 57 cases $(25.7 \%)$ and third most common pituitary adenoma comprised of 30 cases $(13.6 \%)$. The number of individual tumor in detail is tabulated. Table 1 and 2. 


\begin{tabular}{|c|c|c|c|c|c|c|}
\hline \multirow[t]{2}{*}{ Diagnosis } & \multicolumn{6}{|c|}{ Age Group (Years) } \\
\hline & $0-20$ & $21-40$ & $41-60$ & $>60$ & Total & $\%$ \\
\hline Adamantinomatous craniopharyngioma & 2 & 4 & 1 & 3 & 10 & 4.5 \\
\hline Astrocytic tumor & 7 & 22 & 18 & 10 & 57 & 25.7 \\
\hline Oligodendroglioma & 0 & 3 & 3 & 2 & 8 & 3.6 \\
\hline Meningioma & 2 & 25 & 30 & 10 & 67 & 30.3 \\
\hline Central Neurocytoma & 0 & 3 & 0 & 0 & 3 & 1.4 \\
\hline Choroid plexus papilloma & 1 & 0 & 0 & 0 & 1 & 0.5 \\
\hline Ependymoma & 3 & 2 & 0 & 0 & 5 & 2.3 \\
\hline Ganglioglioma & 0 & 0 & 1 & 0 & 1 & 0.5 \\
\hline Hemangioblastoma & 0 & 4 & 0 & 2 & 6 & 2.7 \\
\hline Embryonal tumor & 3 & 0 & 0 & 0 & 3 & 1.4 \\
\hline Metastatic carcinoma & 0 & 1 & 5 & 7 & 13 & 5.9 \\
\hline Oligoastrocytoma & 0 & 5 & 4 & 1 & 10 & 4.5 \\
\hline Pituitary adenoma & 2 & 11 & 14 & 3 & 30 & 13.6 \\
\hline Lymphoma & 0 & 1 & 3 & 3 & 7 & 3.2 \\
\hline Total & 20 & 81 & 79 & 41 & 221 & 100 \\
\hline
\end{tabular}

In the cases of meningioma, there was female preponderance with $\mathrm{M}: \mathrm{F}=1: 3.7)$ (14 males and 53 females) andshowed increased frequency in age group 3 (41-60years). As depicted in table 3 , the meningothelial and transitional meningioma comprised of 26 cases each $(38.8 \%)$ and psammomatous meningioma comprised of 6 cases $(9 \%)$.

Astrocytic tumor showed male preponderance with male to female ratio of $1.4: 1$. It was encountered most frequently in the age group of 21-40years. Among astrocytic tumor 27 cases $(47.4 \%)$ were of glioblastoma multiforme (GBM) seconded by diffuse fibrillary astrocytoma 11(19.3\%) cases. (Table 4) Pituitary adenoma was third in proportion with total case of 30 (13.6\%), showed equal sex predilection and age propensity to clinically manifest among the age group of 41-60 years.

Among the studied total 221 CNS tumors, in 171 cases, it was possible to grade the tumors according to the WHO classification. The frequency of WHO grade I tumor was considerably higher comprising 94 cases (55\%),WHO grade II tumor was 34 cases (19.9\%), WHO grade III tumor was 10 cases $(5.8 \%)$ and WHO grade IV tumor, $33(19.3 \%)$ cases. In this study, WHO grade III tumor was the least, which is shown in bar diagram. (fig.4)

WHO grade IV tumor was higher in age group of 41-60 years $(42.42 \%)$ whereas WHO grade I, II and III tumor showed preponderance in age group $21-40$ years $(38.9 \%$, $61.7 \%$ and $60 \%$ respectively)as depicted in figure 4 .

As the CNS tumors of pediatric age group are considered to have its own spectrum, children of age group range 0-20 years were analyzed in our study as well. There was male preponderance with 14 males and six females, $\mathrm{M}: \mathrm{F}=2.3: 1$ which was contrary to the ratio of overall tumor. The

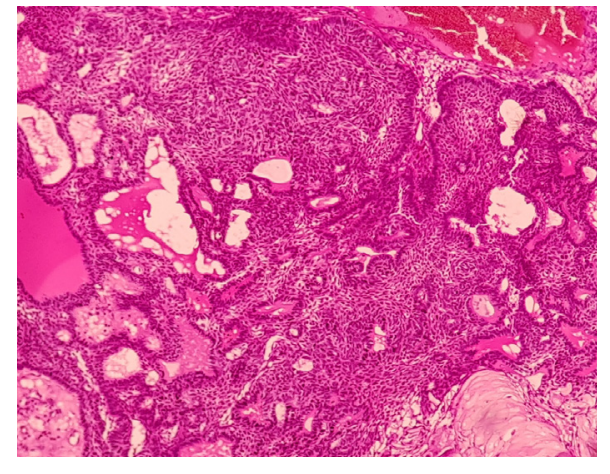

Figure 1: Adamantinomatous craniopharyngioma: Peripheral palisading of squamous epithelium, "'stellate reticulum," and "'wet keratin" (HE stain; X100).

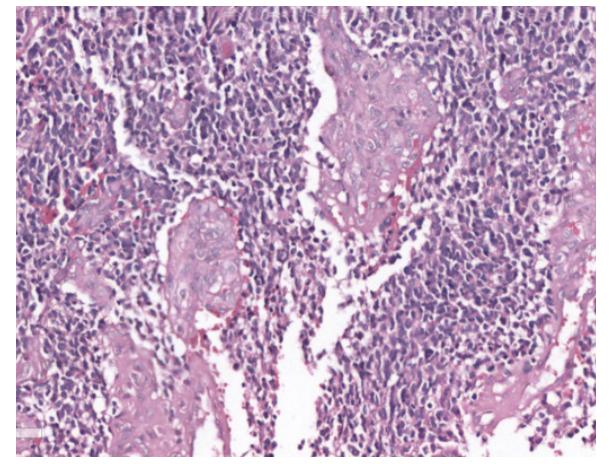

Figure 2: Glioblastoma multiforme with tumor cells with areas of microvascular proliferations (glomeruloid bodies; HE stain; X200). 
Table 3: Relative frequency of meningioma according to age

\begin{tabular}{|c|c|c|c|c|c|c|c|c|c|c|}
\hline \multirow[t]{3}{*}{ Diagnosis } & \multicolumn{6}{|c|}{ Age Group (Years) } & & & & \\
\hline & \multicolumn{2}{|c|}{$<20$} & \multicolumn{2}{|c|}{$21-40$} & \multicolumn{2}{|c|}{$41-60$} & \multicolumn{2}{|c|}{$>60$} & \multicolumn{2}{|c|}{ Total } \\
\hline & $\mathbf{n}$ & $\%$ & $\mathbf{n}$ & $\%$ & $\mathbf{n}$ & $\%$ & $\mathbf{n}$ & $\%$ & $\mathbf{n}$ & $\%$ \\
\hline Meningothelial meningioma & 0 & - & 10 & 40 & 13 & 43.3 & 3 & 30 & 26 & 38.8 \\
\hline Transitional meningioma & 1 & 50 & 12 & 48 & 9 & 30 & 4 & 40 & 26 & 38.8 \\
\hline Fibrous meningioma & 1 & 50 & 1 & 4 & 1 & 3.3 & 0 & - & 3 & 4.5 \\
\hline Microcystic meningioma & 0 & - & 1 & 4 & 1 & 3.3 & 0 & - & 2 & 3 \\
\hline Psammomatous meningioma & 0 & - & 0 & - & 4 & 13.3 & 2 & 20 & 6 & 9 \\
\hline Secretory meningioma & 0 & - & 0 & - & 1 & 3.3 & 0 & - & 1 & 1.5 \\
\hline Angiomatous meningioma & 0 & - & 0 & - & 1 & 3.3 & 1 & 10 & 2 & 3 \\
\hline Atypical meningioma & 0 & - & 1 & 4 & 0 & - & 0 & - & 1 & 1.5 \\
\hline Total & 2 & 100 & 25 & 100 & 30 & 100 & 10 & 100 & 67 & 100 \\
\hline
\end{tabular}

Table 4: Relative frequency of astrocytic tumors according to age

\begin{tabular}{|c|c|c|c|c|c|c|c|c|c|c|}
\hline \multirow[t]{3}{*}{ Diagnosis } & \multicolumn{6}{|c|}{ Age Group (Years) } & & & & \\
\hline & \multicolumn{2}{|c|}{$<20$} & \multicolumn{2}{|c|}{$21-40$} & \multicolumn{2}{|c|}{$41-60$} & \multicolumn{2}{|c|}{$>60$} & \multicolumn{2}{|c|}{ Total } \\
\hline & n & $\%$ & $\mathbf{n}$ & $\%$ & $\mathbf{n}$ & $\%$ & $\mathbf{n}$ & $\%$ & $\mathbf{n}$ & $\%$ \\
\hline Pilocytic astrocytoma & 4 & 57.1 & 3 & 13.6 & 1 & 6.2 & 0 & & 8 & 14 \\
\hline Diffuse gemistocytic astrocytoma & 0 & & 0 & & 1 & 6.2 & 0 & & 1 & 1.8 \\
\hline Diffuse fibrillary astrocytoma & 1 & 14.3 & 9 & 40.9 & 1 & 6.2 & 0 & & 11 & 19.3 \\
\hline Pleomorphic xanthoastrocytoma & 1 & 14.3 & 1 & 4.5 & 0 & & 0 & & 2 & 3.5 \\
\hline Anaplastic astrocytoma & 0 & & 4 & 18.2 & 1 & 6.2 & 0 & & 5 & 8.8 \\
\hline Glioblastoma (Fig.2) & 1 & 14.3 & 5 & 22.7 & 12 & 75 & 9 & 100 & 27 & 47.4 \\
\hline Gliosarcoma & 0 & & 0 & & 2 & & 1 & & 3 & 5.2 \\
\hline Total & 7 & 100 & 22 & 100 & 18 & 100 & 9 & 100 & 57 & 100 \\
\hline
\end{tabular}

frequency of individual tumor is tabulated in table 5 .

In our study there were 13 cases of metastatic carcinoma among which three were squamous cell carcinoma, Adenocarcinoma, ductalcarcinoma, adenoidcysticcarcinoma comprised one each however; eight were categorized as metastatic carcinoma and was sent for the identification of primary site with the help of immunohistochemistry. Other tumors like oligodendroglioma, craniopharyngioma,

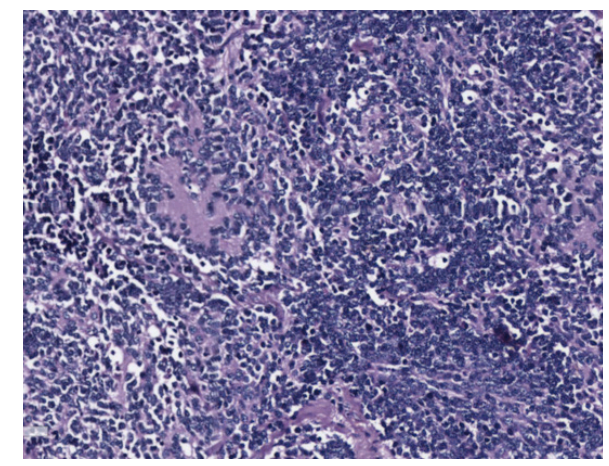

Figure 3: Photomicrograph showing microscopic view of medulloblastoma with small round tumor cells with a Homer-Wright rosette (HE stain; X200). embryonal tumors and ependymomas were seen in different proportions.

\section{DISCUSSION}

The present study comprised of 221 CNS tumors irrespective of age, from a single centre and was categorized according to the recent WHO classification. ${ }^{8}$

\section{Distribution of CNS tumors by sex and age group}

In our study male to female ratio was $\mathrm{M}: \mathrm{F}=1: 1.3$ showing female preponderance $(56.5 \%)$ which is similar to study in Singapore conducted by Das A et $\mathrm{al}^{10}$ with female occupying $52.6 \%$ however, findings of Nibhoria $\mathrm{S}$ et $\mathrm{al}^{11}$ was conflicting with the ratio of $\mathrm{M}: \mathrm{F}=1.2: 1$.

The age group of patients with CNS tumors also corroborated with studies like that of Krishnatreya $\mathrm{M}$ et al in which the highest number of patients was seen in the age-group of 2039 years and $21-40$ years in our study. ${ }^{12}$

\section{Pattern of common CNS tumor}

Meningioma was the commonest tumor $30.3 \%$ which was 


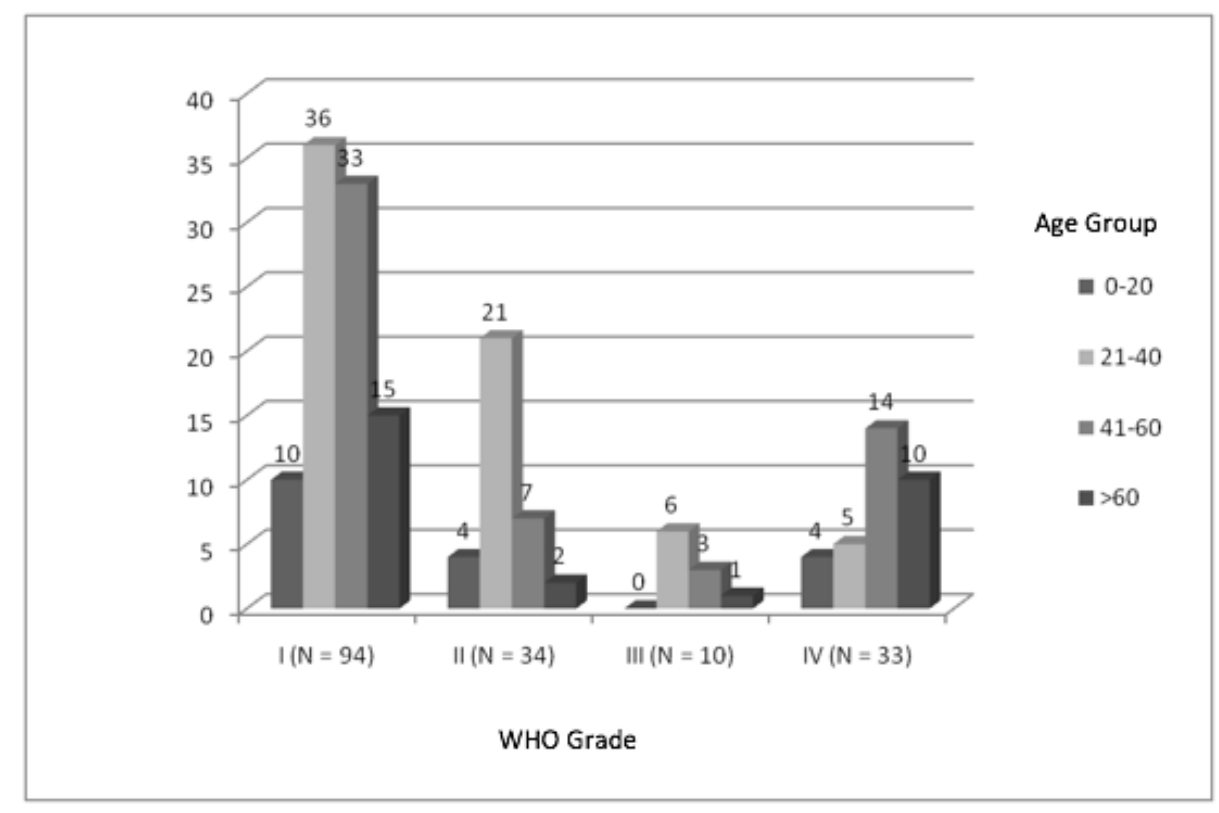

Figure 4: Bar diagram showing relative frequency of various $\mathrm{WHO}$ grade according to age group

\begin{tabular}{|c|c|c|c|c|}
\hline $\begin{array}{c}\text { Age } \\
\text { (years) }\end{array}$ & Diagnoses & Sex & $\mathbf{N}$ & $\%$ \\
\hline$<1$ & Choroid plexus papilloma & M & 1 & 5 \\
\hline 3 & PNET, NOS & M & 1 & 5 \\
\hline 4 & Medulloblastoma (Fig.3) & $\mathrm{F}$ & 1 & 5 \\
\hline 6 & Ependymoma & M & 1 & 5 \\
\hline 10 & Medulloblastoma & M & 1 & 5 \\
\hline \multirow{3}{*}{12} & Craniopharyngioma & M & 2 & 10 \\
\hline & Pilocytic astrocytoma & M & 1 & 5 \\
\hline & Ependymoma & $\mathrm{F}$ & 2 & 10 \\
\hline \multirow{2}{*}{15} & Meningioma & M & 1 & 5 \\
\hline & Pituitary adenoma & $\mathrm{F}$ & 1 & 5 \\
\hline \multirow{2}{*}{17} & Pilocytic astrocytoma & M & 1 & 5 \\
\hline & Ependymoma & M & 1 & 5 \\
\hline \multirow{2}{*}{18} & Pilocytic astrocytoma & M & 3 & 15 \\
\hline & Diffuse astrocytoma & $\mathrm{F}$ & 1 & 5 \\
\hline 19 & GBM & $\mathrm{F}$ & 1 & 5 \\
\hline \multirow[t]{2}{*}{20} & Pituitary adenoma & $\mathrm{F}$ & 1 & 5 \\
\hline & Total & & 20 & \\
\hline
\end{tabular}

comparable with other worldwide studies. Ghanghoria $\mathrm{S}$ et al had similar findings in their study comprising of $41.54 \%$ of meningioma. ${ }^{13}$ Lee et al $^{14}$ in Korea and Jazayeri SB et $\mathrm{al}^{15}$ in Iran also observed that most common tumor was meningioma (31.2\% and $27.8 \%$ respectively). However, our finding is contrasting with the first study conducted in Nepal. Aryal $G$ et al noticed that the most frequent type of CNS tumor was astrocytoma (38.6\%) followed by meningioma (14\%). ${ }^{16}$ Similarly, a meningioma study conducted by Wiemels $\mathrm{J}$ et al showed the prevalence of pathologically confirmed meningioma to be low, reasoning that a proportion of meningioma are not surgically managed, these estimates may be low. ${ }^{17}$

Meningioma showed female predominance in studies of Nibhoria $\mathrm{S}$ et $\mathrm{al}^{11}$ and Thambi $\mathrm{R}^{18}$ similar to our findings. As mentioned earlier the most common histological subtype was transitional meningioma and meningothelial type which corroborated with the data of Thambi $\mathrm{R}$ et al in which transitional meningioma was followed by meningothelial type in frequency. There were $87.5 \%$ of grade I meningioma followed by other grades in her study whereas we encountered $98.5 \%$ of grade one meningioma and a single case was of grade II meningioma. ${ }^{11}, 18$

The second most common astrocytic tumors $(25.7 \%)$ was also a relatable finding to Thambi $\mathrm{R}$ et al $(25 \%) .{ }^{18}$ The peak age group of this tumors was 21 to 40 years according to study conducted by Ayral $\mathrm{G}$ et al which is below our peak range of 41-60 years. ${ }^{16}$ The reason behind this contrasting finding in the same geographical area may be due to the changing time trends of the tumor and should be evaluated and calculated in depth by epidemiological surveys in other institutions of our country. GBM comprised the highest number of astrocytic tumor with frequency of $31.4 \%$, $50.5 \%$ in other studies comparable to our finding of 47.4 percent. ${ }^{10,16}$

This WHO grade IV tumor was seen to be most frequent in the age group 41 to 60 years with a male preponderance. Similar results were obtained in various studies. ${ }^{4,15,19}$ 
The overall WHO grade IV tumor here was found to be highest in age group of 41-60 years (42.42\%). A study conducted by Chen $\mathrm{L}$ et al in china also revealed the data of WHO grade III and IV being most frequent in the age group 40-49 and 50-59 years. In both of the studies the oldest age group did not show propensity towards the highest grade of tumor. $^{4}$

\section{Pattern of distribution of CNS Tumors in children}

The CNS tumors in children and teenagers showed considerable histologic diversity. The disease pattern was found to be different between the age range of 0-10 years and 12-20 years. The earlier age group showed prevalence of embryonal tumors whereas the older ages suffered more from astrocytic tumors. This similar variance in the distribution of tumors in children was also noticed by Lee $\mathrm{CH}$ et al but the differentiating age was from $0-14$ and 1520 years. The most common tumor was astrocytic tumor comprising of $37 \%$ (7/20cases); a slightly higher than the findings of Lee $\mathrm{CH}$ et $\mathrm{al}^{14}$ and NibhoriaS et $\mathrm{al}^{11}$ ( $25 \%$ and $29.2 \%$ resp.) but it was in concordance with Jain et $\mathrm{al}^{20}$ with proportion of 34.7 percent.

Pediatric GBM is not very common as adult. In our study a case of GBM was seen in a 19 years female. Ansari M et al had studied GBM in paedriatic age group 0-20 years, their mean age was 15.2 years and the median age 16 years. ${ }^{21}$

\section{CONCLUSION}

This study showed the most common CNS tumor to be meningioma followed by astrocytic tumors and pituitary adenoma. The spectrum of CNS tumor in children showed divergent histologic pattern according to the age. In age group 0-10 years embryonal tumors were common whereas ages group of 12-20 years showed propensity towards astrocytoma as in adults.

Undeterred by great innovations in ancillary studies, the simple H\&E stained slides continue to exist as an invaluable means to diagnose and classify CNS tumors. This study may contribute to revise the changing patterns of incidence, mortality, survival and prevalence of CNS tumors in our part of the world.

\section{Conflict of interest: None}

\section{REFERENCES}

1. Murthy N S, Mathew A. Cancer epidemiology, prevention and control. Curr Sci 2004;86:518-527.

2. Moore A. Overview of Cancer Registration Research in the Asian Pacific from 2008-2013. Asian Pacific J Cancer Prev 2013;14:446184. $\underline{\text { Crossref }}$

3. Dasgupta A, Gupta T, Jalali R. Indian data on central nervous tumors: A summary of published work. The South Asian Journal of Cancer 2016;5:147-53. Crossref
4. Chen L, Zou X, Wang Y, Mao Y, Zhou L. Central Nervous system tumours: a single center pathology review of 34,140 cases over 60 years. BMC ClinPathol 2013;13:14. Crossref

5. Kurland LT, Schoenberg BS, Annegers JF, Okazaki H, and Molgaad $\mathrm{CA}$. The incidence of primary intracranial neoplasms in Rochester, Minnesota 1935-1977. Ann. N.Y. Acad. Sci1982;381:6-16. Crossref

6. Al Hussaini M. Histology of primary brain tumors. INTECH,2013;10:145-80. Crossref

7. Louis DN, Ohgaki H, Wiestler OD, et al. The 2007 WHO classification of tumors of the central nervous system. Acta Neuropathol 2007;114:97-109. Crossref

8. Louis DN, Ohgaki H, Wiestler OD, Cavenee WK. Editors. World Health Organization Classification of Tumors of the Central Nervous System. Lyon: IARC; 2007.

9. Kleihues P, Burger PC, Scheithauer BW. The new WHO classification of brain tumours. Brain Pathol 1993;3:255-68. Crossref

10. Das A, Chapman CAT ,Yap WM.Histological subtypes of symptomatic central nervous system tumours in Singapore. J Neurol Neurosurg Psychiatry 2000;68:372-4. Crossref

11. Nibhoria S, Tiwana KK, Phutela R, Bajaj A, Chhabra S, Bansal S. Histopathological Spectrum of Central Nervous System Tumors: A Single Centre Study of 100 Cases. Int J Sci Stud 2015;3:1304.

12. Krishnatreya M, Kataki AC, Sharma JD, Bhattacharyya M, Nandy P, Hazarika M. Brief Descriptive Epidemiology of Primary Malignant Brain Tumors from North-East India. Asian Pac J Cancer Prev 2014;15:9871-3. Crossref

13. Ghanghoria S, Mehar R, Kulkarni CV, Mittal M, Yadav A, Patidar H. Retrospective histological analysis of CNS tumors - A 5 year study. Int J Med Sci Public Health 2014;3:1205-07. Crossref

14. Lee CH, Jung KW, Yoo H, et al. Epidemiology of primary brain and central nervous system tumors in Korea. J Korean Neurosurg Soc 2010;482:145-52. Crossref

15. Jazayeri SB, Rahimi-Movaghar V, ShokranehF,Saadat S, Ramezani R. Epidemiology of Primary CNS Tumors in Iran: A Systematic Review.Asian Pacific J Cancer Prev 2013;14:3979-85. Crossref

16. Aryal G. Histopathological pattern of central nervous system tumor: A three year retrospective study. J Pathol Nep 2011;1:22-5. Crossref

17. Wiemels J, Wrensch M, Claus EB. Epidemiology and etiology of meningioma. J Neurooncol 2010;99:307-14.

18. Thambi R, Kandamuthan S, Sainulabdeen S, et al.Histopathological Analysis of Brain Tumours- A Seven Year Study from a Tertiary Care Centre in South india. Journal of Clinical and Diagnostic Research 2017;11:05-08. Crossref

19. Schwartzbaum JA, Fisher JL, Aldape KD, Wrensch M Epidemiology and molecular pathology of glioma. Nat. Clin. Pract Neurol 2006;2:494-503. $\underline{\text { Crossref }}$

20. Jain A, Sharma MC, Suri V, et al. Spectrum of pediatric brain tumors in India: A multi-institutional study.Neurol India 2011;59:208-11. Crossref

21. Ansari M, Nasrolahi H, Kani AA, et al. Pediatric glioblastoma multiforme: A single-institution experience. Indian Journal of Medical and Paediatric Oncology: Official Journal of Indian Society of Medical \& Paediatric OncologyN2012;33:155-60. 